\title{
Does the Bull Market Have "Buffett"?-An Empirical Study on Chinese Mutual Fund Value Investing in Bull and Bear Markets
}

\author{
Weijian Yan \\ Department of Finance, School of Economics, Jinan University, Guangzhou, China \\ Email: 865843623@qq.com
}

How to cite this paper: Yan, W.J. (2017) Does the Bull Market Have "Buffett"?-An Empirical Study on Chinese Mutual Fund Value Investing in Bull and Bear Markets. Technology and Investment, 8, 108-120. https://doi.org/10.4236/ti.2017.82009

Received: March 29, 2017

Accepted: May 23, 2017

Published: May 26, 2017

Copyright $\odot 2017$ by author and Scientific Research Publishing Inc. This work is licensed under the Creative Commons Attribution International License (CC BY 4.0).

http://creativecommons.org/licenses/by/4.0/

\section{(c) (i) Open Access}

\begin{abstract}
"Worshipping value investing in the bear market and everyone is 'Buffett' in the bull market" is a general impression of China's stock market. This article uses the open-end fund holdings data from 2006 to 2015 to test whether the investment behavior of fund consistent with value investing both in the bear market and the bull market. This paper finds that the stock with higher fund holdings in the bear market is positively related to the next quarter and the next year's unexpected earnings, but not in the bull market. At the same time, similar conclusions have been drawn from further analysis of the new-in and new-out investment behaviors. Overall, this paper demonstrates that "the bear market follows the value investment, while the bull market ignores the value investment" has some truths.
\end{abstract}

\section{Keywords}

Mutual Fund, Bear and Bull Markets, Investment Behavior, Unexpected Earnings

\section{Introduction}

At the end of 2016 there are more than 3000 open-end funds in Chinese capital market, many of which in its investment philosophy, said the "value investing" words, as one of its means of propaganda. However, the so-called "value investing", in fact, is that the mutual fund uses research, access and other methods to obtain relevant information and make decisions. It is generally accepted that the mutual fund, as an "informative trader" with information superiority, compared to the general investors with more the fundamentals of listed companies and other information, can effectively assess the value of listed companies and implement value investing [1] [2] [3]. Based on this idea, it is easy to think that the 
mutual fund as a rational investor regardless of bear market or bull market should maintain the same investment philosophy, adhere to value investing.

However, the reality of the market is that the mutual funds often show the irrational behavior as the general investors, such as the herding effect; seeking after a variety of hot theme stocks, over-optimistic in the bull market; showing a serious investment style drift and with the stock market trend drift changes significantly; the fund managers have different stock picking and timing abilities in the bear and bull markets, and in the bull market they performed much cautious; the fund investors tend to chase the performance in the bull market, while they tend to ignore the performance in the bear market, which makes the fund managers have different incentives; increasing the stock volatility. With these phenomena, it naturally brings a question: whether the mutual fund meets the value investment? Whether they stand on end in the bear market? People have always been the view is correct? These issues are of great importance, both for the general investors in the market and for policy management. In particular, in 2016 the Chinese government began to introduce the reform of the registration system, the Chinese stock market will be more concerned about the stock valuation, performance and other factors. Naturally, mutual fund managers should focus on the value investment.

In the study of the value investment, the scholars generally use financial indicators to define the value stocks and growth stocks, and treat the value information as a property of the stock to study. In the actual investment, the mutual fund and other institutional investors make decision by a variety of factors, not only the financial information. So the mutual fund achieves the value investing because of its information superiority. This article studied the fund's value investment from the view of information superiority. In the research of the performance of information superiority, scholars generally concentrate on research the relationship of risk adjustment, stock price and fund performance, and then infer their stock picking and timing abilities. In the weak efficiency market like China, the information is not necessarily reflected to the stock price in time, thereby affecting the fund performance. As a result, some scholars research fund's information superiority from the company's performance. However, it often overlooked the fund's different attitudes to the value investment in the different arena. It is one thing to have the ability of information mining, and the other is to carry on the value investment according to the information. Different from previous studies, this paper takes into account the different investors' expectations, structure, psychology and trading mechanism under different market conditions.

We begin our analysis by examining the impact of the shareholding ratio of the fund to a period of unexpected earnings. This paper uses the data of the top ten awkwardness of the open-end fund from 2006 to 2015 to test whether the investment behavior of the fund in line with the value investing, with the unexpected earnings as the proxy variable. Mutual fund released all of its shares in the semi-annual report and the annual report, and only the top ten holdings of 
the fund will be disclosed in the quarterly report, which we call them the top ten awkwardness.

Next, we examine how the different market conditions affect the relation of the shareholding ratio of the fund and unexpected earnings. For the definition of the bull market and bear market, scholars usually adopt market return rate comparison with a preset threshold, which below the threshold is defined as the downlink interval or "bear market" otherwise defined as uplink interval or "bull market". Kao uses the average monthly market rate of return over the past 12 months to be greater than 0 defined as "bull market". In addition [4], Capocci and Mansor use stock market movements and iconic events to divide the bear market [5] [6]. Study also lessons from the financial investment community to define the market based on market ups and downs of positive and negative $20 \%$ in the past year and whether the annual rate of return of the Shanghai Composite Index is greater than 0 .

Considering the characteristics of China's stock market-"bull short and bear long" and quarterly frequency, as well as the recognition degree of China's fund to bull market and bear market and the actual trend of China's stock market, this paper divided 40 quarters from the first quarter of 2006 to the fourth quarter of 2015 into "bull, bear, bull" three stages, based on the line up and down through the 250 day moving average. Specifically divided into: the first quarter of 2006 to the first quarter of 2008 ( $288 \%$ up); the second quarter of 2008 to the second quarter of (54\% down); the second quarter of 2014 to the fourth quarter of 2015 (73\% up).

The contribution of this paper is: 1) expand the value of investment research, join the bear market and bull market to study the fund's value investment. Different from previous studies, only a period of time to test the value of the investment problem, and it ignores the subjective psychological changes in the real investment; 2) An empirical approach is provided to explain the market impression of "the bear market follows the value investment, while the bull market ignores the value investment". The reason is that under different market conditions, the expression of the fund's information superiority is different.

The remainder of the paper is organized as follows. The second part is the literature review and research hypothesis; the third part is the empirical analysis; the fourth part is the conclusion and the suggestion.

\section{Literature Review and Research Hypothesis}

For the question of how to judge the value of a company in the current period, there are inconsistent opinions in the various disciplines of accounting and finance. But if the historical data is used to look at it, it is easy to find the value information of a company, such as company mergers, company dividends, stock yields rise, the company's performance gains and so on. In this paper, we apply accounting earnings commonly used in empirical accounting studies as a measure of stock value [7] [8] [9]. At the same time, Porter believes that in the case of asymmetric information, investors can't predict the company's long-term value 
with limited company information [10]. So investors are more inclined to predict the company's short-term value. In this paper, combined with the above considerations, within a year for the time to determine whether the fund can effectively predict the future value of the company, and select the current period, the next quarter and the next year three time points to determine the fund's short, medium and long-term investment.

As to whether the fund has the information superiority as an informed trader and can predict the future accounting earnings, many scholars at home and abroad have put forward their own views from different angles. Chen argues that the fund has the ability to forecast its share price, and compared to the current stock sold, the future performance of the current stock bought is significantly better [11]; Ke \& Petroni believes that institutional investors will practice value investing based on the company's accounting earnings information [8]. Yao Yi believes that the fund has the ability to predict company's future value and its investment behavior in line with value investing. Zhang believes that the fund can tap the fundamentals of large companies and access to private information, is the real "informed traders"; Kong believe that the fund can access the listed companies to obtain information superiority, and obtain investment profits by this way. The above literature to a certain extent that the fund as an informed trader have information superiority, and can predict future accounting earnings. Based on this discussion, the following hypotheses are advanced.

$\mathrm{H} 1$ : Overall, the shareholding ratio of the fund is positively related to a period of unexpected earnings and the fund has a certain value investing ability.

The difference between bear market and bull market is that in the bull market, because of the large amount of money into the stock market, the stock price will rise in general, including even bad company's performance stock, so the performance may not be necessarily in the bull market for investment decision-making considerations. Xiao believes that the fund's investment style will drift in the bear market and bull market, and more likely to grow or balanced type, while the lack of value. Xiao believes that fund managers show different attitudes towards fund performance in bear market and bull market. Xiao suggested that the expected risk adjustment performance of the fund is different in the bear market and bull market. These phenomena naturally make the fund's investment philosophy change, resulting in a general impression that "the bear market follows the value investment, while the bull market ignores the value investment". Based on this discussion, the following hypotheses are advanced.

$\mathrm{H} 2$ : The shareholding ratio of the fund in the bear market is positively related to unexpected earnings in a given period. The shareholding ratio in the bull market is not significantly related to any period of unexpected earnings.

The above assumptions can only show that the shares held by the fund show the value in the future for a certain period of time, and they can't explain the fund's investment basis for the value investment. True value investment performance of the fund is that it shall use its "information superiority" status, when the stock value is increased to buy, sell the stock when its value is expected to 
decline. So further through the fund investment behavior to determine whether the fund in line with the value of investment, but also test it in bear market and bull market, to make more robust conclusions. Based on this discussion, the following hypotheses are advanced.

H3a: The shareholding ratio of the new-in shares of the fund is positively related to unexpected earnings of a given period. The shareholding ratio of the new-out stock is negatively correlated with unexpected earnings of a certain period.

H3b: The shareholding ratio of the new-in shares of the fund in the bear market is positively related to unexpected earnings of a certain period. The shareholding ratio of the new-in shares of the fund in the bull market is not significantly related to unexpected earnings of any period.

$\mathrm{H} 3 \mathrm{c}$ : The shareholding ratio of the new-out shares of the fund in the bear market is negatively related to unexpected earnings of a certain period. The shareholding ratio of the new-out shares of the fund in the bull market is not significantly related to unexpected earnings of any period.

\section{Empirical Analysis}

\subsection{Sample Selection and Data Sources}

The data come from the WIND database. WIND is the market leader in China's financial information services industry, similar to Bloomberg in USA. We selected the top ten awkwardness as research sample, disclosed from the first quarter of 2006 to the fourth quarter of 2015, totally 40 quarters. We removed 1) 58 CSRC financial stocks; 2) special treatment (st) shares during the sample period; 3) stocks listed for one year and less than one year; 4) missing data stock, and received a sample data of 160,702 quarterly positions held by mutual fund. After that, we calculated the shareholding ratio of each stock, so as to get the full sample data and the new-in and new-out sample data based on different investment behavior of the fund.

\subsection{Model Setting}

\subsubsection{Variable Definition}

Combined with the literature researched the fund investment behavior [12] [13], we calculate Fund ratio, the shareholding ratio of the fund, as the aggregate ownership of our final sample of the fund.

We use Standardized Unexpected Earnings (SUE) as the explained variable, which widely used in previous studies [14] [15]. Following Ball's method [7], the per-share earnings follows a random walk, and we can use the actual earnings for the current period as the forecast value of current, when we want to estimate the expected earnings. Using the standard approach from Ball [7], Unexpected Earnings $(U E)$ measures according to

$$
U E_{i, t}=E p s_{i, t}-E\left(E p s_{i, t}\right)=E p s_{i, t}-E p s_{i, t-1},
$$

where $i$ indexes stocks and $t$ indexes quarter, Eps $s_{i, t}$ is earnings per share. 
Next, we calculate Standardized Unexpected Earnings (SUE) following Foster $[14]$ as

$$
S U E_{i, t}=U E_{i, t} /\left|E p s_{i, t-1}\right|,
$$

Considering the influence of firm size, profitability and equity distribution on the investment behavior of the fund, this paper uses $M v_{i, t}$, the natural logarithm of the market value of A shares; Eps $s_{i, t}$, earnings per share; Bigholder ${ }_{i, t}$, the proportion of the largest shareholder as the control variable. At the same time, control the effect of the stock market on Turnover $_{i, t}$, the average daily turnover of each stock and $\mathrm{Vol}_{i, t}$, the average daily amplitude of each stock.

\subsubsection{Empirical Model}

Our model builds on the models by Kim [16] and Bushee [17]. This model suggests that it is possible to determine whether or not to obtain value information based on the relationship between the investor's trading behavior and the fundamentals (earnings) information indicators at different points in time. According to this, this paper uses the panel data fixed effect model:

$$
\begin{aligned}
\text { Fundratio }_{i, t}= & \beta_{1} \text { SUE }_{i, 0}+\beta_{2} \text { SUE }_{i, 1}+\beta_{3} \text { SUE }_{i, 4} \\
& +c\left(\text { Controls }_{i, t}\right)+\text { Stock }_{i}+\text { Quarter }_{t}+\varepsilon_{i, t}
\end{aligned}
$$

The index $\mathrm{i}$ in the model (3) represents stock, the subscript $t$ represents the period, and $S U E_{i, 0}$ indicates the unexpected earnings of the current period, $S U E_{i, 1}$ represents the unexpected earnings of the next quarter, $S U E_{i, 4}$ represents the unexpected earnings of the next year, Controls $s_{i, t}$ represents the control variables, Stock $k_{i}$ said control individual fixed effect, Quarter $_{t}$ said control time fixed effect.

\subsection{The Empirical Results}

\subsubsection{Descriptive Statistics}

Table 1 shows the whole sample period data for the entire sample period and regardless of the fund's investment behavior, and descriptive statistics of $1 \%$ and $99 \%$ extreme values for all variables. From the statistical results, the fund's

Table 1. Sample descriptive statistical analysis.

\begin{tabular}{ccccccc}
\hline Variable & Mean & Median & Std. Dev. & Min & Max & $\mathrm{N}$ \\
\hline Fundratio $_{i, t}$ & 5.313 & 2.579 & 6.817 & 0.001 & 32.727 & 21600 \\
SUE $_{i, 0}$ & 0.317 & 0.048 & 1.864 & -5.210 & 12.000 & 21600 \\
SUE $_{i, 1}$ & 0.279 & 0.031 & 1.879 & -6.000 & 12.000 & 21600 \\
SUE $_{i, 4}$ & 0.084 & -0.025 & 1.793 & -8.333 & 10.375 & 21600 \\
Eps $_{i, t}$ & 0.334 & 0.220 & 0.377 & -0.267 & 1.980 & 21600 \\
Mv $_{i, t}$ & 13.342 & 13.274 & 1.031 & 11.200 & 16.187 & 21600 \\
Bigholder $_{i, t}$ & 37.356 & 36.106 & 15.728 & 8.940 & 75.840 & 21600 \\
Turnover $_{i, t}$ & 2.379 & 1.850 & 1.876 & 0.092 & 9.317 & 21600 \\
Vol $_{i, t}$ & 44.654 & 36.080 & 28.908 & 9.842 & 172.785 & 21600 \\
\hline
\end{tabular}


Awkwardness's unexpected earnings is positive, whether it is current $S U E_{i, 0}$ (0.317), the next quarter $S U E_{i, 1}(0.279)$ and the next year $S U E_{i, 4}(0.084)$. This means that on average, the fund's Awkwardness has a better future value. Holdings of the fund awkwardness generally conform to the value investing. However, the mean values of $S U E_{i, 0}, S U E_{i, 1}$ and $S U E_{i, 4}$ show a decreasing trend, indicating that the average judgment of the fund on the value of Awkwardness is the closer, Lack of value investing judgment. From the results of Table 1, the fund's Awkwardness is on average conform to the value investing, but whether the fund's shareholding is significantly positively correlated with unexpected earnings, these issues need to be further through the empirical data for testing. All the analysis we are done with Stata 12.0.

\subsubsection{Shareholding Ratio and Unexpected Earnings}

From the first column of Table 2, we can see that the shareholding ratio of the fund is positively correlated with the unexpected earnings in the next quarter $S U E_{i, 1}$, with a coefficient of 0.069 , which is significant at $1 \%$ level. The shareholding ratio of the fund was not significant with the current unexpected earnings $S U E_{i, 0}$ and the next year's unexpected earnings $S U E_{i, 4}$. On the whole, the

Table 2. Results of the shareholding ratio and unexpected earnings.

\begin{tabular}{|c|c|c|c|}
\hline \multirow{2}{*}{ Variable } & (1) & (2) & (3) \\
\hline & whole & bear & bull \\
\hline \multirow{2}{*}{$S U E_{i, 0}$} & -0.007 & -0.005 & -0.027 \\
\hline & $(-0.27)$ & $(-0.25)$ & $(-0.58)$ \\
\hline \multirow[t]{2}{*}{$S U E_{i, 1}$} & $0.069^{* * *}$ & $0.106^{* * *}$ & -0.002 \\
\hline & $(2.99)$ & $(4.31)$ & $(-0.05)$ \\
\hline \multirow[t]{2}{*}{$S U E_{i, 4}$} & 0.019 & $0.037^{* *}$ & -0.004 \\
\hline & $(0.96)$ & $(2.35)$ & $(-0.32)$ \\
\hline \multirow[t]{2}{*}{$E p s_{i, t}$} & $2.818^{\star * *}$ & $3.045^{* * *}$ & $1.278^{\star * *}$ \\
\hline & $(7.23)$ & $(8.22)$ & $(2.82)$ \\
\hline \multirow[t]{2}{*}{$M v_{i, t}$} & $2.031^{* * *}$ & $2.445^{* * *}$ & $2.872^{\star * *}$ \\
\hline & $(6.13)$ & $(10.20)$ & $(5.13)$ \\
\hline \multirow[t]{2}{*}{ Bigholder $_{i, t}$} & 0.018 & 0.015 & $0.056^{* * *}$ \\
\hline & $(1.40)$ & $(0.99)$ & $(4.88)$ \\
\hline \multirow[t]{2}{*}{ Turnover $_{i, t}$} & $-0.535^{\star * \star}$ & $-0.360^{* * *}$ & $-0.867^{\star * *}$ \\
\hline & $(-7.91)$ & $(-8.10)$ & $(-5.11)$ \\
\hline \multirow[t]{2}{*}{$\mathrm{Vol}_{i, t}$} & $0.032^{* * *}$ & $0.025^{* * *}$ & $0.027^{* * *}$ \\
\hline & $(7.02)$ & $(4.48)$ & $(4.29)$ \\
\hline \multirow[t]{2}{*}{ Constant } & $-16.733^{* * *}$ & $-26.611^{\star * *}$ & $-25.726^{* * *}$ \\
\hline & $(-3.78)$ & $(-7.78)$ & $(-3.72)$ \\
\hline Quarter Fixed Effect & Yes & Yes & Yes \\
\hline Observations & 22,000 & 15,000 & 6,745 \\
\hline$R^{2}$ & 0.172 & 0.128 & 0.315 \\
\hline
\end{tabular}

Note: Coefficients marked with ${ }^{\star * \star},{ }^{\star *}$, and ${ }^{\star}$ are significant at $1 \%, 5 \%$, and $10 \%$ level, respectively. 
mutual fund is in line with medium-term value investments and can tap into the company's next quarter's value information. This conclusion in line with Yao Yi et al. (2011) found that China's funds have the medium-term performance of listed companies to predict the ability to invest in the medium-term value of listed companies. Funds do not meet short-term and long-term value investing, can't dig into the company's current and next year's value information or not short-term and long-term value information for investment decision-making basis. In general, $\mathrm{H} 1$ is true.

\subsubsection{Shareholding Ratio and Unexpected Earnings in the Bear and Bull Market}

In the empirical test of $\mathrm{H} 2$, the sample period is divided into bear market and bull market respectively. It can be seen from the second column of Table 2 that the shareholding ratio of the fund in the bear market is positively correlated with the unexpected earnings in the next quarter $S U E_{i, 1}$ and the unexpected earnings in the next year $S U E_{i, 4}$, and the coefficients are 0.106 and 0.037 , respectively. But the next quarter's coefficient is greater, indicating that the fund for the medium-term value of the information is more accurate forecast. The coefficient of unexpected earnings for the next year is not significant in the whole sample period, and there is a significant difference in the bear market, indicating that the fund is considered more long-term in the bear market and is more cautious and will take into account the company's value information for the next year.

As can be seen from column 3 of Table 2, the shareholding ratio of the fund in the bull market is not significantly related to any one of the unexpected earnings. This indicates that the fund can't be excavated in the bull market to the value of the information or not to short, medium and long-term value of information for investment decision-making basis.

To sum up the $\mathrm{H} 2$ set up, and it can determine that "the bear market follows the value investment, while the bull market ignores the value investment", but it still can't determine the fund is not mining the value of the information or not short, medium and long-term value information for investment decision basis. In order to test the fund as a "informed trader", with the ability to tap the value of information, and to make investment decisions, then this article further join the fund investment behavior, test whether the fund is doing value investing, and how it perform in the bear and bull market, respectively.

\subsubsection{Shareholding Ratio and Unexpected Earnings under Different Investment Behaviors}

This paper reclassifies the sample data of the 160,702 fund company quarterly stockpile according to the investment behavior of the fund to generate new-in stock samples and new-out stock samples. The new-in stock is the new stock in the current quarter's top ten Awkwardness but not in the last quarter; the new-out stock is the stock belonged to the last quarter's top ten Awkwardness but not the current. 
As can be seen from column 1 of Table 3, the shareholding ratio of the fund is positively correlated with the unexpected earnings in the current quarter $S U E_{i, 1}$, with a coefficient of 0.046 , significant at $1 \%$. It means that the fund will buy stocks with medium-term value. From the coefficients of $S U E_{i, 0}$ and $S U E_{i, 4}$, although they aren't significant, but are positive, indicating that the basic value of the stock bought by the fund will not be too bad. As can be seen from column 1 of Table 4, the shareholding ratio of the fund in the new-out stock is significantly positively correlated with the current's unexpected earnings $S U E_{i, 0}$, with a factor of 0.031 , significant at $1 \%$, but the coefficients from $S U E_{i, 1}$ and $S U E_{i, 4}$ are negative, indicating that the fund will sells the stock exactly when the stock is good, thus avoiding bad performance. It can speculate that the fund may have the ability to sell rallies.

It can be seen from column 2 of Table 3 that the shareholding ratio of the new-in stocks in the bear market is significantly positively correlated with the unexpected earnings $S U E_{i, 1}$ in the next quarter, with a coefficient of 0.071 , compared with 0.046 of the overall sample period to be high, indicating that the fund in the bear market more value investing. And the current unexpected

Table 3. Fund shareholding ratio and unexpected earnings of new-in stocks.

\begin{tabular}{|c|c|c|c|}
\hline \multirow{2}{*}{ Variable } & (1) & (2) & (3) \\
\hline & whole & bear & bull \\
\hline \multirow{2}{*}{$S U E_{i, 0}$} & 0.000 & -0.015 & 0.006 \\
\hline & $(-0.00)$ & $(-0.78)$ & $(0.34)$ \\
\hline \multirow[t]{2}{*}{$S U E_{i, 1}$} & $0.046^{* * *}$ & $0.071^{* * *}$ & -0.020 \\
\hline & $(2.97)$ & $(4.40)$ & $(-0.83)$ \\
\hline \multirow[t]{2}{*}{$S U E_{i, 4}$} & 0.011 & 0.013 & -0.009 \\
\hline & $(0.87)$ & $(0.79)$ & $(-0.52)$ \\
\hline \multirow[t]{2}{*}{$E_{p s}$} & $0.778^{\star * *}$ & $0.769^{* * *}$ & $0.389^{*}$ \\
\hline & $(4.93)$ & $(5.89)$ & $(1.91)$ \\
\hline \multirow[t]{2}{*}{$M v_{i, t}$} & $0.335^{* *}$ & $0.508^{\star * *}$ & $0.710^{* * *}$ \\
\hline & $(2.43)$ & $(3.96)$ & $(3.85)$ \\
\hline \multirow{2}{*}{ Bigholder $_{i, t}$} & $0.014^{* *}$ & 0.008 & $0.027^{* * *}$ \\
\hline & $(2.27)$ & $(1.02)$ & $(3.92)$ \\
\hline \multirow[t]{2}{*}{ Turnover $_{i, t}$} & $-0.169^{* * *}$ & $-0.100^{* * *}$ & $-0.369^{* * *}$ \\
\hline & $(-4.51)$ & $(-3.17)$ & $(-4.45)$ \\
\hline \multirow[t]{2}{*}{$V_{o l} l_{i, t}$} & $0.033^{\star * \star}$ & $0.037^{\star * \star}$ & $0.029^{* * *}$ \\
\hline & $(9.43)$ & $(9.53)$ & $(6.74)$ \\
\hline \multirow[t]{2}{*}{ Constant } & -0.651 & $-4.679^{* * *}$ & $-4.549^{\star *}$ \\
\hline & $(-0.35)$ & $(-2.68)$ & $(-2.10)$ \\
\hline Quarter Fixed Effect & Yes & Yes & Yes \\
\hline Observations & 18,000 & 12,000 & 5,876 \\
\hline$R^{2}$ & 0.177 & 0.119 & 0.281 \\
\hline
\end{tabular}

Note: Coefficients marked with ${ }^{\star * *},{ }^{* *}$, and ${ }^{\star}$ are significant at $1 \%, 5 \%$, and $10 \%$ level, respectively. 
Table 4. Fund shareholding ratio and unexpected earnings of new-out stocks.

\begin{tabular}{|c|c|c|c|}
\hline \multirow{2}{*}{ Variable } & (1) & (2) & (3) \\
\hline & whole & bear & bull \\
\hline \multirow[t]{2}{*}{$S U E_{i, 0}$} & $0.031^{* * *}$ & $0.044^{* * *}$ & -0.021 \\
\hline & $(2.73)$ & $(3.11)$ & $(-1.00)$ \\
\hline \multirow[t]{2}{*}{$S U E_{i, 1}$} & -0.018 & $-0.024^{* *}$ & 0.013 \\
\hline & $(-1.15)$ & $(-2.04)$ & $(0.76)$ \\
\hline \multirow[t]{2}{*}{$S U E_{i, 4}$} & -0.001 & -0.007 & -0.009 \\
\hline & $(-0.05)$ & $(-0.22)$ & $(-0.20)$ \\
\hline \multirow[t]{2}{*}{$\operatorname{Eps}_{i, t}$} & $0.886^{\star * *}$ & $0.860^{* * *}$ & $0.303^{*}$ \\
\hline & $(6.37)$ & $(4.14)$ & $(1.71)$ \\
\hline \multirow[t]{2}{*}{$M v_{i, t}$} & $0.657^{\star * \star}$ & $0.709^{* * *}$ & $1.178^{\star * *}$ \\
\hline & $(7.31)$ & $(9.22)$ & $(4.92)$ \\
\hline \multirow[t]{2}{*}{ Bigholder $_{i, t}$} & $0.017^{\star *}$ & $0.019^{* *}$ & $0.022^{\star *}$ \\
\hline & $(2.26)$ & $(2.03)$ & $(2.24)$ \\
\hline \multirow[t]{2}{*}{ Turnover $_{i, t}$} & $-0.165^{\star * *}$ & $-0.103^{\star *}$ & $-0.500^{\star \star \star}$ \\
\hline & $(-3.49)$ & $(-2.46)$ & $(-6.24)$ \\
\hline \multirow[t]{2}{*}{$V l_{i, t}$} & $0.016^{\star * *}$ & $0.017^{* * *}$ & $0.018^{* * *}$ \\
\hline & $(5.63)$ & $(6.68)$ & $(4.34)$ \\
\hline \multirow[t]{2}{*}{ Constant } & $-4.402^{\star * *}$ & 0.000 & $-9.502^{\star * *}$ \\
\hline & $(-3.45)$ & . & $(-3.07)$ \\
\hline Quarter Fixed Effect & Yes & Yes & Yes \\
\hline Observations & 17,000 & 12,000 & 4,478 \\
\hline$R^{2}$ & 0.137 & 0.101 & 0.221 \\
\hline
\end{tabular}

Note: Coefficients marked with ${ }^{* * *},{ }^{* *}$, and ${ }^{*}$ are significant at $1 \%, 5 \%$, and $10 \%$ level, respectively.

earnings $S U E_{i, 0}$ is negative, indicating that the fund is biased towards the left. It can be seen from column 2 of Table 4 that the shareholding ratio of the fund in new-out stocks in the bear market is significantly positively correlated with the unexpected earnings $S U E_{i, 0}$, with a coefficient of 0.044; $S U E_{i, 1}$ was significantly negative correlation with a coefficient of -0.024 , indicating that the fund is also sold at rallies, and accurately predict the performance of the stock will be bad performance.

The above analysis shows that regardless of the whole or in the bear market, the Fund's trading behavior in line with the value investing standard, that is, when the stock value is expected to buy, is expected to decline in value when sold. But also side of the Fund has the ability to tap the value of information.

As can be seen from column 3 of Table 3, the shareholding ratio of new-in stocks in the bull market is not significantly related to any unexpected earnings, even the coefficient of $S U E_{i, 1}$ and $S U E_{i, 4}$ are negative. Similarly, as can be seen from column 3 of Table 4, the shareholding ratio of new-out stocks in the bull market is not significantly related to any unexpected earnings. Through the previous analysis above, whether in the whole or in the bear market, the Fund 
has a certain value of information mining capabilities, but to the bull market did not show it. This article discusses the fund as a whole, rather than a single fund, so in general this ability will not change because of different market conditions. It is very likely that the fund in the bear market based on the value of information as the basis for investment decisions, and in the bull market is not mining the value of the information but not short, medium and long-term value of information for investment decision-making basis.

To sum up, through the fund investment behavior to further prove that the Fund in the bear market meets value investing in the bull market does not meet the value investing.

\section{Conclusions}

This paper uses the data of the top ten awkwardness of the open-end fund from 2006 to 2015 to test whether the investment behavior of the fund in line with the value investing, with the unexpected earnings as the proxy variable. The conclusions are as follows:

First of all, this article found that to the top ten awkwardness in 2006 to 2015 the entire sample period, the shareholding ratio of the fund is significantly positively correlated with the unexpected earnings in the next quarter, indicating that the fund is heavily loaded with the stock are generally medium-term value of the stock, indicating that the fund has at least a certain value investment.

Secondly, when the sample period is divided into bear market and bull market to explore the different market conditions under the fund's holding style has changed. The results show that the increase or decrease in the shareholding ratio of the fund in the bear market is positively related to the unexpected earnings in the next quarter and the next year, indicating that the holdings are generally medium-term and long-term stocks, indicating that the fund has a certain forecast of long-term value information capacity, while the increase or decrease in the shareholding ratio in the bull market is not significantly related to any unexpected earnings, indicating that the stock with a high shareholding ratio does not show significant value information in the future.

Finally, we want to further confirm that the fund has the ability to invest in value, that is, when the value of the stock is expected to buy, it is expected to decline in value when sold, rather than the sample of bear market in the future value just outstanding. 1) In the bear market, the increase or decrease in the shareholding ratio of the new-in stocks are positively related to the unexpected earnings in the next quarter, which is consistent with the value of the stock The ratio of the fund holdings of the new-out stocks is significantly positively correlated with the unexpected earnings of the current period, which is significantly negatively correlated with the unexpected earnings of the next quarter, which is in line with the expected decline in the value of the stock. This shows that in the bear market, in line with the value investing. 2) In the bull market, the increase or decrease in the shareholding ratio of new-in and new-out stocks are not significantly related to any unexpected earnings and does not meet the value in- 
vesting, indicating that the Fund has a certain value in the investment capacity, in the bull market to give up value investing.

\section{Further Study}

This paper uses the data of China's open-end funds to make the analysis. If the accession to other institutional investors, such as brokerage, insurance, QFII, etc., does it get the same conclusion? It still needs further study. At the same time, it would be more convincing to compare and analyze other countries with different market maturity. What's more, this paper mainly studies the relationship between the fund holdings and the unexpected earnings, the future can be further added to the listed company's stock price, fund performance and other factors.

\section{References}

[1] Rajan, R.G. (1994) Why Bank Credit Policies Fluctuate: A Theory and Some Evidence. The Quarterly Journal of Economics, 109, 399-441. https://doi.org/10.2307/2118468

[2] Devenow, A. and Welch, I. (1996) Rational Herding in Financial Economics. European Economic Review, 40, 603-615. https://doi.org/10.1016/0014-2921(95)00073-9

[3] Bushee, B.J., Jung, M.J. and Miller, G.S. (2011) Conference Presentations and the Disclosure Milieu. Journal of Accounting Research, 49, 1163-1192. https://doi.org/10.1111/j.1475-679X.2011.00426.x

[4] Kao, G.W., Cheng, L.T.W. and Chan, K.C. (1998) International Mutual Fund Selectivity and Market Timing during Up and Down Market Conditions. Financial Review, 33, 127-144. https://doi.org/10.1111/j.1540-6288.1998.tb01373.x

[5] Capocci, D., Corhay, A. and Hübner, G. (2005) Hedge Fund Performance and Persistence in Bull and Bear Markets. The European Journal of Finance, 11, 361-392. https://doi.org/10.1080/1351847042000286676

[6] Mansor, F. and Bhatti, M.I. (2011) Islamic Mutual Funds Performance for Emerging Market, during Bullish and Bearish: The Case of Malaysia. 2nd International Conference on Business and Economic Research, Langkawi, 14-16 March 2011, 770-789.

[7] Ball, R. and Brown, P. (1968) An Empirical Evaluation of Accounting Income Numbers. Journal of Accounting Research, 6, 159-178. https://doi.org/10.2307/2490232

[8] Ke, B. and Petroni, K. (2004) How Informed Are Actively Trading Institutional Investors? Evidence from Their Trading Behavior before a Break in a String of Consecutive Earnings Increases. Journal of Accounting Research, 42, 895-927. https://doi.org/10.1111/j.1475-679X.2004.00160.x

[9] Bushee, B.J. (2001) Do Institutional Investors Prefer Near-Term Earnings over Long-Run Value? Contemporary Accounting Research, 18, 207-246. https://doi.org/10.1506/J4GU-BHWH-8HME-LE0X

[10] Porter, M.E. (1991) Capital Disadvantage: America's Failing Capital Investment System. Harvard Business Review, 70, 65-82.

[11] Chen, H.L., Jegadeesh, N. and Wermers, R. (2000) The Value of Active Mutual Fund Management: An Examination of the Stockholdings and Trades of Fund Managers. Journal of Financial and quantitative Analysis, 35, 343-368. 
https://doi.org/10.2307/2676208

[12] Agarwal, V., Fos, V. and Jiang, W. (2013) Inferring Reporting-Related Biases in Hedge Fund Databases from Hedge Fund Equity Holdings. Management Science, 59, 1271-1289. https://doi.org/10.1287/mnsc.1120.1647

[13] Agarwal, V., Mullally, K.A., Tang, Y., et al. (2015) Mandatory Portfolio Disclosure, Stock Liquidity, and Mutual Fund Performance. The Journal of Finance, 70, 2733 2776. https://doi.org/10.1111/jofi.12245

[14] Foster, G., Olsen, C. and Shevlin, T. (1984) Earnings Releases, Anomalies, and the Behavior of Security Returns. Accounting Review, 59, 574-603.

[15] Frazzini, A. (2006) The Disposition Effect and Underreaction to News. The Journal of Finance, 61, 2017-2046. https://doi.org/10.1111/j.1540-6261.2006.00896.x

[16] Kim, O. and Verrecchia, R.E. (1997) Pre-Announcement and Event-Period Private Information. Journal of Accounting and Economics, 24, 395-419. https://doi.org/10.1016/S0165-4101(98)00013-5

[17] Bushee, B.J. and Goodman, T.H. (2007) Which Institutional Investors Trade Based on Private Information about Earnings and Returns? Journal of Accounting Research, 45, 289-321. https://doi.org/10.1111/j.1475-679X.2007.00234.x

Submit or recommend next manuscript to SCIRP and we will provide best service for you:

Accepting pre-submission inquiries through Email, Facebook, LinkedIn, Twitter, etc. A wide selection of journals (inclusive of 9 subjects, more than 200 journals) Providing 24-hour high-quality service User-friendly online submission system Fair and swift peer-review system Efficient typesetting and proofreading procedure Display of the result of downloads and visits, as well as the number of cited articles Maximum dissemination of your research work

Submit your manuscript at: http://papersubmission.scirp.org/

Or contact ti@scirp.org 